\title{
NeW APPROACH For OEE CALCULATION OF CNC MACHINES BASED ON OPC UA
}

\section{Ayatollahi I.; HaCKhofer M.; KitTl B. \& PAuKer F.}

Abstract: Industry is driven by efficiency, only this makes it possible to assert competitive advantage in the global market. Many companies use Overall Equipment Effectiveness (OEE) as a Key Performance Indicator (KPI). Currently the International Organization for Standardization (ISO) is working on standardized definitions of KPIs for Manufacturing Execution Systems (MES), based on VDMA 66412. The aim of this paper is to present a service oriented approach to OEE calculation based on ISO/DIS 22400-2 for CNC machines deployed in individual production using OPC Unified Architecture (OPC UA) as an information modelling and data transport technology. In contrast to conventional procedures for OEE calculation, where a huge amount of data is collected from shop floor level and analyzed at the supervisory level, we suggest that Key Performance Indicators are calculated as close as possible to the data sources.

Key words: OEE, OPC UA, ISO/DIS 22400-2, VDMA 66412, Key performance indicators
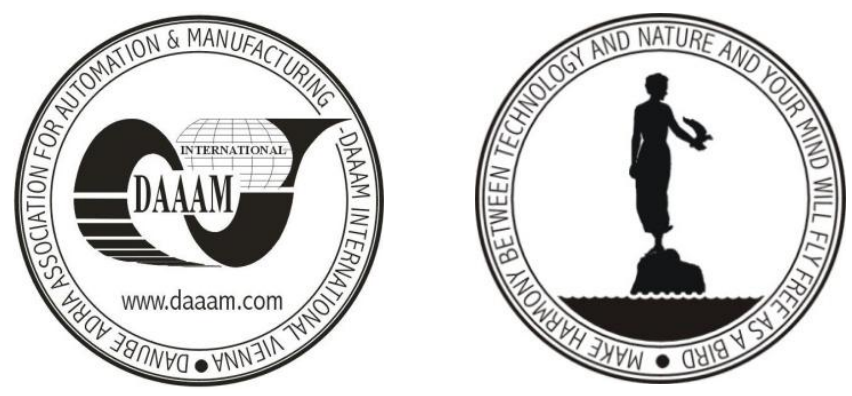

Authors' data: Ayatollahi I[man $]^{*}$; Ao.Univ.Prof. Dipl.-Ing. Dr.techn. Kittl B[urkhard]*; MSc. Pauker F[lorian]*; MSc. Hackhofer M[artin]**, * University of Technology, Karlsplatz 13, 1040, Vienna, Austria, **Hackhofer EDV, Im Aichetfeld 45, 4490, St. Florian, Austria; * University of Technology, Karlsplatz 13, 1040, Vienna, Austria, ayatollahi@ift.at, kittl@ift.at, pauker@ift.at

This Publication has to be referred as: Ayatollahi, I[man]; Hackhofer, M[artin]; Kittl, B[urkhard] \& Pauker, F[lorian] (2013) New Approach for Oee Calculation of Cnc Machines Based on Opc Ua, Chapter 55 in DAAAM International Scientific Book 2013, pp. 895-902, B. Katalinic \& Z. Tekic (Eds.), Published by DAAAM International, ISBN 978-3-901509-94-0, ISSN 1726-9687, Vienna, Austria

DOI: $10.2507 /$ daaam.scibook.2013.55 
Ayatollahi, I.; Hackhofer, M.; Kittl, B. \& Pauker, F.: New Approach for Oee Calcul...

\section{Introduction}

In the manufacturing industry Overall Equipment Effectiveness (OEE) is used as a common key figure for manufacturing facilities. OEE as a measurement method is part of the Total Productive Maintenance (TPM) concept. It was first implemented 1971 at Nippondenso Co. which was member of the Toyota Group (Reichel et al., 2009). The OEE has been proven in thousands of companies. It exposes relentlessly losses and helps eliminating them (Koch, 2011). It presents a key figure which is composed of the factors availability, effectiveness and quality rate. Usually the OEE is applied for mass production and only in few exceptions for individual production. Due to the lack of a precise OEE definition, many derivations evolved in the last years, among them the following exist:

- "Overall line effectiveness" (OLE) (Nachiappan and Anantharaman, 2006)

- "Overall equipment effectiveness of a manufacturing line" (OEEML) (Braglia et al., 2008)

- "Overall plant effectiveness" (OPE) (Scott and Pisa, 1998)

- "Overall factory effectiveness" (OFE) (Oechsner et al., 2002)

- "Overall equipment effectiveness of a manufacturing line" (OEEML) (Braglia et al., 2008)

- "Overall fab effectiveness" (OFE) (Oechsner et al., 2002)

- "Determination of the overall equipment effectiveness for assembly systems on the base of product data" (Neugebauer, R., 2010)

- "Stochastic overall equipment effectiveness" (Zammori et al., 2011)

All these methods follow their own definition on how to calculate the OEE. With ISO/DIS 22400-2 which is based on the VDMA 66412 published in 2009, a "Draft International Standard" is now available. The subcommittee 184 with working group 9 of the International Organization for Standardization (ISO) works on this standard, which is currently guided as in "Enquiry stage" (ISO, n.d.). In ISO/DIS 22400-2 the OEE is defined as follows:

$$
\begin{gathered}
\mathrm{OEE}=\text { Availability } \cdot \text { Effectiveness } \cdot \text { Quality rate } \\
\text { Availability }=\frac{A P T}{P B T}=\frac{\text { Actual production time }}{\text { Planned busy time }} \\
\text { Effectiveness }=\frac{P R U \cdot P Q}{A P T}=\frac{\text { Planned running time per unit } \times \text { Produced quantity }}{\text { Actual production time }} \\
\text { Quality rate }=\frac{G Q}{P Q}=\frac{\text { Good quantity }}{\text { Produced quantity }}
\end{gathered}
$$




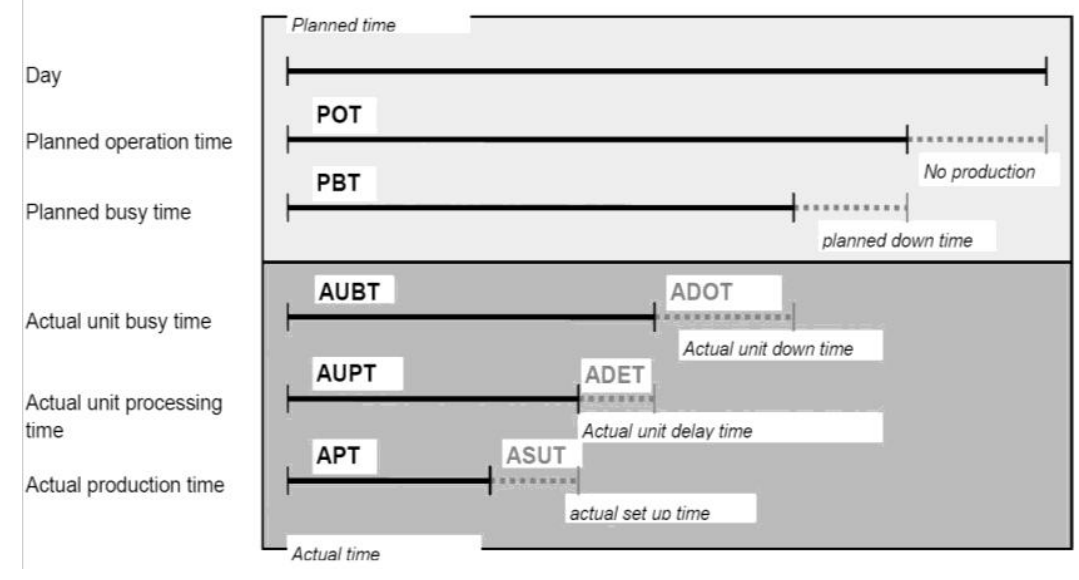

Fig. 1. Timeline for production units (ISO, n.d.)

The OEE should be understood as aggregated information based on detailed information mostly created at the shop floor level. Therefore, machines as information providers should be able to evaluate relevant KPIs (e.g. effectiveness) and automatically deliver these indicators to higher-level systems or to machine operators. This would correlate with the paradigm of service oriented architecture (SOA).

\subsection{Communication between Shop Floor and MES}

Currently with VDI 5600 a guideline for communication between machines and MES is available which also considers existing standards from MESA, NAMUR, ISA, VDMA and ZVEI. The standard follows the requirement to be usable for heterogeneous machine parks in the manufacturing industry and does not follow industry-specific standards such as Weihenstephaner Standard, SECS/GEM, MTConnect (VDI, 2011). In VDI 5600 part 3 a well defined data structure for communication between a machine as a production resource and an MES System is presented. Since the communication technology itself is not scope of VDI 5600, in this paper OPC Unified Architecture (OPC UA) is suggested as a promising specification to facilitate semantic communication.

\subsection{OPC Unified Architecture (OPC UA)}

The most recent specification developed by the OPC Foundation - OPC UA is capable of permeating the whole information and communication structure of enterprises, and can be seen as a Service Oriented Architecture. "The purpose of OPC Unified Architecture was to enable a platform-independent interoperability standard for moving data/information between the factory floor and the enterprise"(Mahnke et al., 2009). The previous standard of the OPC Foundation, the classic OPC, is widely used in industry for data access and is still more common than the successor standard. 


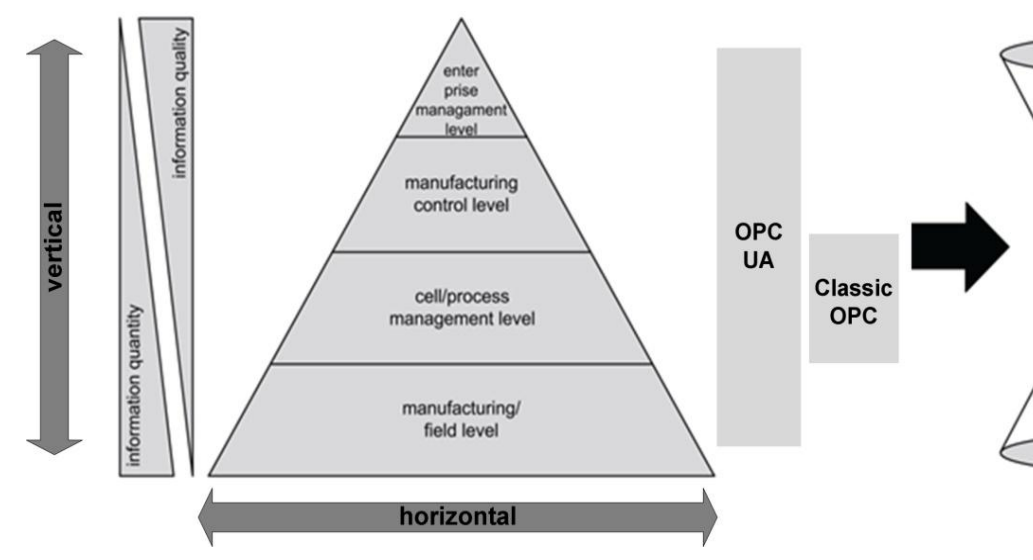

Fig. 2. Automation pyramid vs. new perception

In Fig. 2. the possible range of use of OPC UA and classic OPC is shown for interfacing the layers of the automation pyramid from device level up to the enterprise level. With ISA-95 and OAGIS ("Open Applications Group," n.d.) two important standards for integrating applications based on service-oriented architecture are available (Gifford et al., 2006). Both provide a more cost-effective way for organizations to integrate their applications vertically in the information and communication technology view and should therefore be considered for OPC UA integrations. Great hopes are placed in OPC UA as a new communication standard for manufacturing systems, e.g. robotized manufacturing cells. Currently the full functional volume of OPC UA is not yet used in the field of production engineering. At best it is used only as a wrapper for data access.

\section{Proposed Approach}

To comply with manufacturing enterprises' demands, new approaches to determine performance indicators are needed. The widespread automation pyramid shown in Fig. 2 represents a layer model of information technology for production enterprises. It is based on the opposing trend of information quality versus information quantity. Today this model is not consistent with the reality anymore (Kegel, 2010). Due to the wide integration of information technology, a new reference model is required, that has to include the vertical and horizontal dimensions of information flow as well as the life cycle of the product (Kegel, 2010).

The presented approach for OEE calculation follows the paradigm of a Service Oriented Architecture (SOA). In contrast to conventional procedures for OEE calculation, where a huge amount of data is collected from shop floor level and analyzed at the supervisory level, we suggest that Key Performance Indicators are calculated as close as possible to the data sources.

Fig. 3 shows the information flow between the supervisory system (MES) and the shop floor for OEE evaluation, using the proposed approach. OEE is calculated in the supervisory system from availability, quality ratio and effectiveness. Availability is the ratio of actual production time (APT) which can be delivered by the machine, and the planned busy time (PBT) which can be obtained from job shop scheduling. 
Quality ratio is calculated from good quantity (GQ) and produced quantity (PQ) delivered by order confirmation through shop floor data collection terminals. Effectiveness is based on data generated in the machine and will be calculated in the machine. We suggest the implementation of an OPC UA server in the machine tool control allowing the supervisory system to query actual production time (APT) and effectiveness for a given evaluation period through OPC UA method calls. The input parameters are the start and end times of the evaluation period. They can be chosen by a machine operator or automatically by the MES (e.g. automatic evaluation of effectiveness for each job). APT and effectiveness are calculated using equations (5) and (6) for the given time interval using historized data on the OPC UA server.

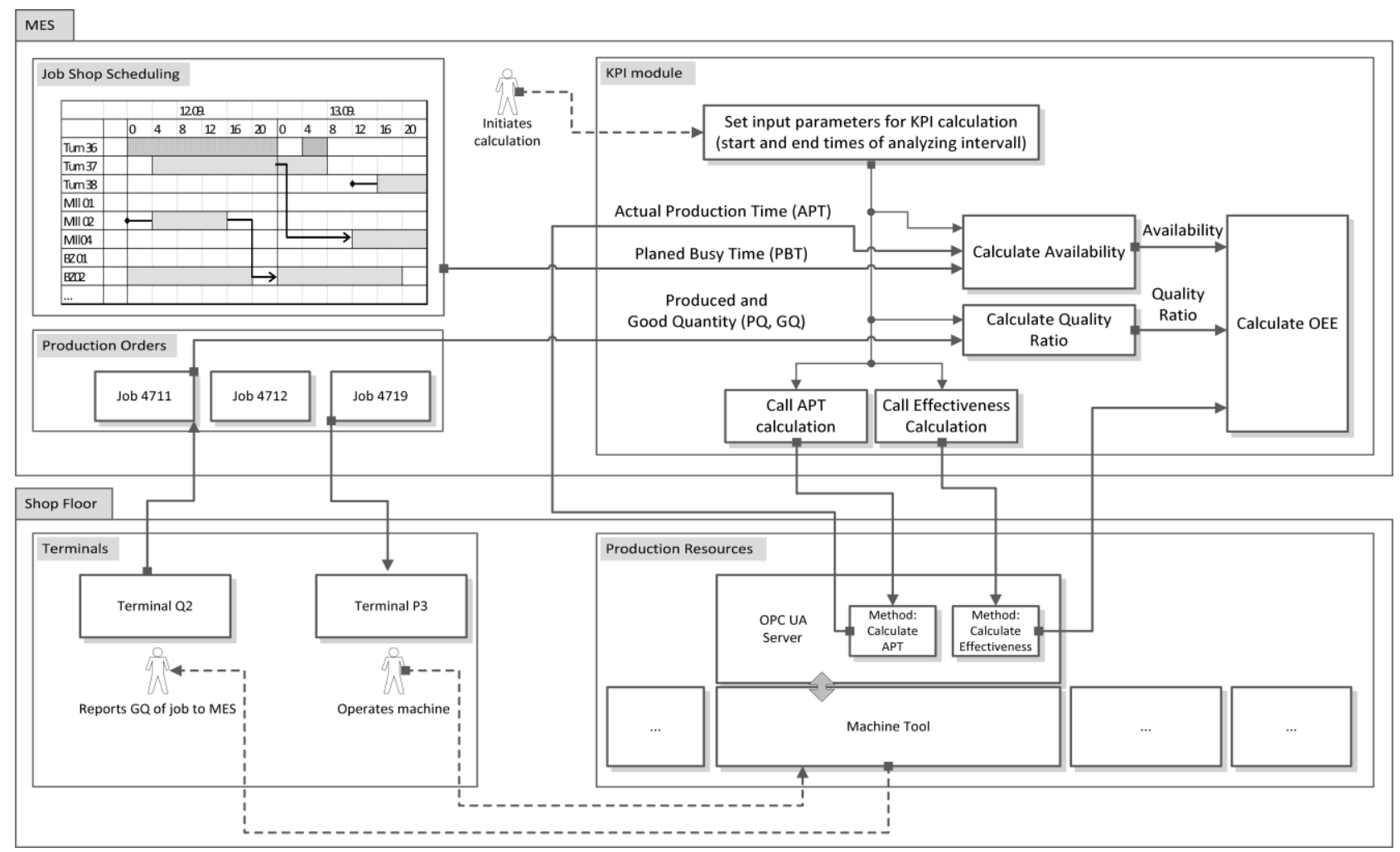

Fig. 3. Proposed information flow between MES and the shop floor

\subsection{Calculating the actual Production Time (APT)}

In case of CNC machine tools the machine status can be "inactive" (no machining), "active" (machining in progress) or "fault" (machining interrupted). APT can be understood as the time where machining is in progress. In Fig. 4 an exemplary sequence of relevant machine status changes is illustrated as a set of time slices. Each time slice represents either a production time (active) or a downtime (inactive or fault). Using equation (5) APT can be calculated with the given input values $t_{\text {start }}$ and $t_{\text {end }}$. These values are first compared with the historized timestamps of the OPC UA variable, which represents the machine status. The slices are then indexed as shown in Fig. 4. The time slice in which $t_{\text {start }}$ or $t_{\text {end }}$ falls into are split to correspond to the given time horizon. For each slice the historized machine status is checked to determine if the slice represents an inactive or fault period $\left(a_{i}=0\right)$ or an active period $\left(\mathrm{a}_{\mathrm{i}}=1\right)$. 
Ayatollahi, I.; Hackhofer, M.; Kittl, B. \& Pauker, F.: New Approach for Oee Calcul...

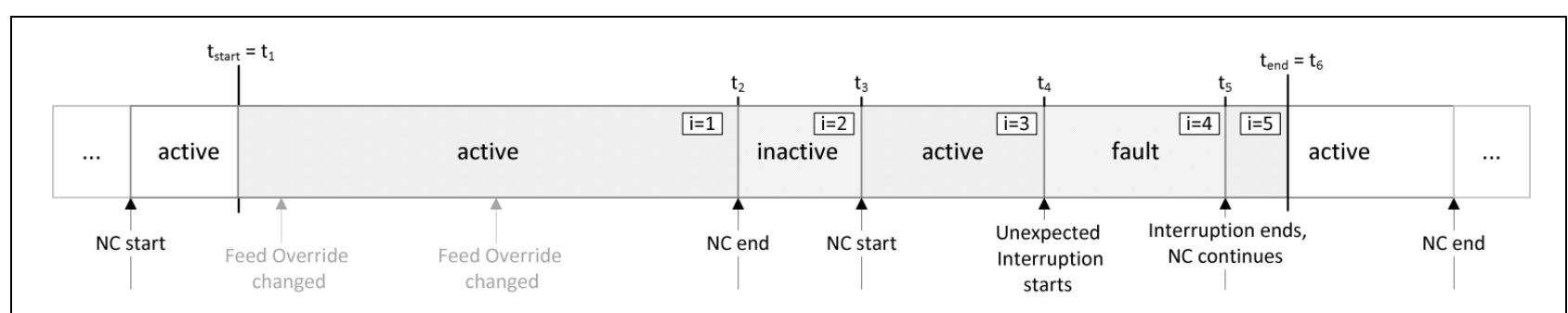

Fig. 4. Example of time slices for evaluating APT

$$
A P T_{t_{\text {start }}}^{t_{\text {end }}}=\sum_{i=1}^{n}\left[a_{i} \cdot\left(t_{i+1}-t_{i}\right)\right]
$$

\subsection{Calculation of Effectiveness}

For evaluating the effectiveness according to equation (3) the product of planned run time per unit (PRU) and the produced quantity (PQ) is needed. For individual production the PRU is often roughly estimated or delivered by a CAM (Computer Aided Manufacturing) System as the result of machining simulation. We propose a simple solution instead. In case of $\mathrm{CNC}$ machining the planned run time can be defined as the processing time with planned machining parameters. That is when the machine operates with programmed feed rates and when no unplanned interruptions occur. If the feed rates are changed by feed override during machining, the processing time will obviously change. With knowledge about the feed override values and the timestamps for feed override changes the "planned run time" (PRU * PQ) can be calculated using equation (6), with $f_{i}$ as the feed override value of time slice $i$ $\left(0<\mathrm{f}_{\mathrm{i}}<1.2\right)$ and $\mathrm{a}_{\mathrm{i}}=\{0,1\}$.

$$
(P R U \cdot P Q)_{t_{\text {start }}}^{t_{\text {end }}}=\sum_{i=1}^{n}\left[a_{i} \cdot f_{i} \cdot\left(t_{i+1}-t_{i}\right)\right]
$$

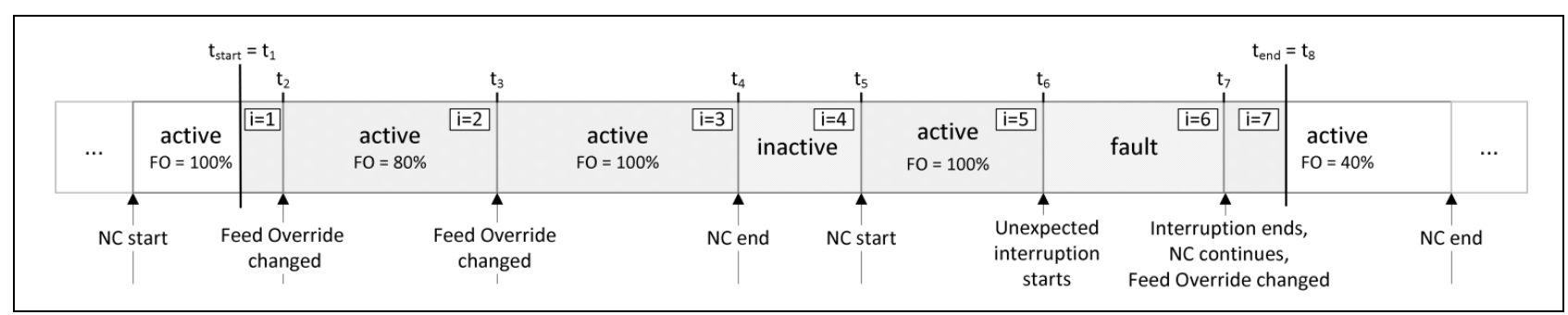

Fig. 5. Example of time slices for calculating effectiveness

\section{Prototype Implementation of the New Approach}

At the Institute for Production Engineering and Laser Technology (IFT), Vienna University of Technology, a prototype OPC UA server had been developed for the lathe "Emco Concept Turn 55", which is mainly used for industrial training (Ayatollahi et al., 2013). The OPC UA server runs in the numerical control of the machine tool. The server was not only developed for data collection by overlaying systems, but also to allow remote control of the machine tool using OPC UA 
methods. As part of ongoing further development of the OPC UA server the presented approach has been integrated into the address space of the machine tool (Fig. 6). Since the MES-Machine interface is not scope of this development, we just implemented the above mentioned calculations as OPC UA methods. The data needed for evaluating APT and effectiveness of the machine is the historized status variables "Machine_Status" and "Feed_Override". In this prototype the value of "Machine_Status" can have three different string values. Whenever the value is "active" the factor $a_{i}$ for that time slice in equations (5) and (6) is set to 1 , in any other case its set to 0 . The variable "Feed_Override" is an integer and its value is between 0 and 120. The appropriate values for use in equation (6) as $f_{i}$ are therefore divided by 100 .

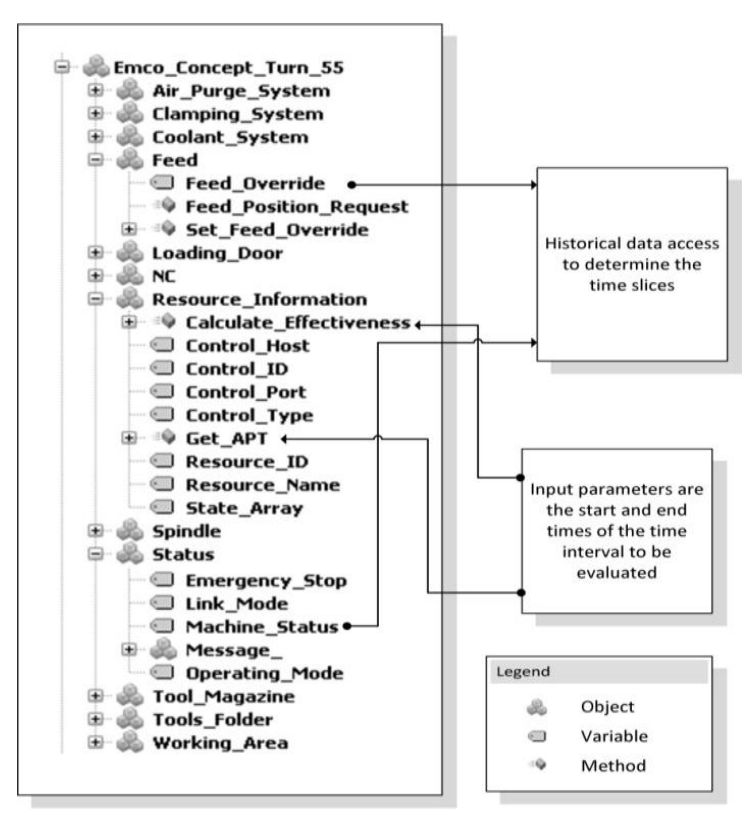

Fig. 6. Address space of the OPC UA server

\section{Conclusion}

The prototype development described in this paper is an attempt to relocate parts of the OEE calculation to the machine level. Evaluation of some KPIs like effectiveness, which only need data generated by the machine, can be integrated into an OPC UA server directly at machine level. Obtaining the planned run time (PRU * $\mathrm{PQ}$ ) through calculations from actual timestamps generated during manufacturing is plausible since the NC program run time only can be affected by unplanned interruptions (fault) or changes of the feed rate. Both events can be monitored by the OPC UA server and used for the adjustment of the planned run time. Today in many manufacturing companies KPIs are evaluated at management levels. Feedback regarding the performance of operations at shop floor reaches the machine operators with a certain delay. Since operators can have strong influence on the performance of production units, especially in case of small batch sizes and individual production, up-to-date KPI calculation close to the data source seems promising. For further testing and verification the suggested approach shall be implemented in an actual production environment as a next step. 
Ayatollahi, I.; Hackhofer, M.; Kittl, B. \& Pauker, F.: New Approach for Oee Calcul...

\section{References}

Ayatollahi, I., Kittl, B., Pauker, F., Hackhofer, M. (2013). Prototype OPC UA server for remote control of machine tools, Proceedings of International Conference on Innovative Technologies, Car, Z. (Ed.), pp. 73-76, ISBN 978-953-6326-88-4, Budapest, September 2013

Braglia, M., Frosolini, M., Zammori, F. (2008). Overall equipment effectiveness of a manufacturing line (OEEML): An integrated approach to assess systems performance. J. Manuf. Technol. Manag., (12/2008), (8-29), ISSN: 1741-038X

Gifford, C., delaHostria, E., Noller, D., Childress, L., Boyd, A. (2006). Standards for Manufacturing Systems Integration ISA-95 and OAGIS - White Paper \#1: An Overview and Comparison, ISA-95/OAGIS Manufacturing Integration Standards White Paper Serie, MESA

ISO. (2011), Automation systems and integration-Key performance indicators for manufacturing operations management-Part 2 (ISO/DIS 22400-2), ISO

Kegel, G., 2010. Neue Informationsarchitektur in der ind. Automatisierung (New information arch. in ind. automation), Karlsruher Leittechnisches Kolloquium, pp. 315, ISBN: 3839601304, Stuttgart, (June, 2010), Fraunhofer Verlag

Koch, A., 2011. OEE für das Produktionsteam: das vollständige OEEBenutzerhandbuch (OEE for the production team: the complete OEE user manual), CETPM, ISBN: 3940775045, Ansbach

Mahnke, W., Leitner, S.-H., Damm, M. (2009). OPC Unified Architecture, Springer Verlag, ISBN 3540688986, Berlin Heidelberg

Nachiappan, R.M., Anantharaman, N., 2006. Evaluation of overall line effectiveness (OLE) in a continuous product line manufacturing system. J. Manuf. Technol. Manag., 17(7), (987-1008), ISSN 1741-038X

Neugebauer, R., (2010). Determination of the overall equipment effectiveness for assembly systems on the base of product data, Sustainable Production and Logistics in Global Networks, Proceedings of 43rd CIRP International Conference on Manufactoring Systems, Kuhlang, P. (Ed.), pp. 991-998, ISBN 978-3-7083-0686-5, Vienna, (May 2010)

Oechsner, R., Pfeffer, M., Pfitzner, L., Binder, H., Müller, E., Vonderstrass, T. (2002). From overall equipment efficiency (OEE) to overall Fab effectiveness (OFE). Mater. Sci. Semicond. Process., Vol 5, Issues 4-5, (333-339), (August-October 2002), ISSN: 1369-8001

Open Applications Group, Avail.: http://www.oagi.org/dnn2/ Accessed:2013-01-24 Reichel, J., Müller, G., Mandelartz, J. (2009). Betriebliche Instandhaltung (Plant Maintenance), Springer, ISBN 978-3-642-00502-2, Berlin Heidelberg

Scott, D., Pisa, R., 1998. Can overall factory effectiveness prolong Moores law ElectroIQ. Solid State Technol. Vol 41, 75-82

VDI, (2011). Fertigungsmanagementsysteme - Blatt 3 (Manufacturing Execution Systems - Part 3), VDI 5600

Zammori, F., Braglia, M., Frosolini, M. (2011). Stochastic overall equipment effectiveness. Int. J. Prod. Res. 49.2011, 19/21, (2011), (pp. 6469-6490), ISSN 00207543 